\title{
PROCESSO DE INERTIZAÇÃO DO REJEITO DE PERFURAÇÃO E SOLO IMPACTADO: TRATAMENTO DOS LÍQUIDOS RECIRCULANTES
}

\author{
B. I. O. VIEIRA, D. J. SILVA, H. G. FERNANDES e O. CHIAVONE-FILHO \\ Universidade Federal do Rio Grande do Norte, Departamento de Engenharia Química \\ E-mail para contato: beatrizidalina@hotmail.com
}

\begin{abstract}
RESUMO - Durante a extração do petróleo ocorre a produção de uma corrente aquosa denominada água de produção de petróleo. Este efluente contém compostos orgânicos e inorgânicos de alta periculosidade, e seu destino tem sido um desafio para a indústria de petróleo e gás. Dessa forma, esta pesquisa propõe uma alternativa para a inertização desses compostos através do processo de Flotação por Ar Induzido (FAI), esta operação unitária apresenta simplicidade, alta eficiência na remoção de contaminantes, capacidade para médias e altas vazões, baixo custo operacional e tempo de residência curto, o que implica em menores espaços e economia na construção. Para avaliar este método, foram analisados os teores de carbono orgânico (TOC) e inorgânico (IC) para a água produzida e industrial, de modo a observar a quantidade de contaminante após o processo.
\end{abstract}

\section{INTRODUÇÃO}

É necessária a evolução e inovação na cadeia produtiva do petróleo, que tem se tornado muito importante na matriz energética brasileira e mundial. Diante disso, novas tecnologias são necessárias para manutenção da sua sustentabilidade. Durante a extração do petróleo ocorre a produção de uma corrente aquosa denominada água de produção de petróleo. Este efluente contém, geralmente, alta salinidade, óleo, diversos compostos orgânicos como benzeno, tolueno, etilbenzeno e xileno (BTEX), naftaleno, fenantreno, dibenzotiofeno (NFD), hidrocarbonetos poliaromáticos (HPA), fenóis, gases e metais pesados (Neff, 2002).

O principal resíduo gerado na etapa de perfuração dos poços de petróleo são os denominados cascalhos de perfuração, misturas de pequenos fragmentos de rochas advindos dos fluidos usados na perfuração, sejam eles os fluidos do próprio solo ou mesmo o utilizado para resfriar e lubrificar a broca. Este cascalho é causador de potenciais impactos ao solo e água subterrânea e são classificados como resíduos sólidos devido sua potencial periculosidade, podem adquirir valor comercial se tratados de forma adequada, ao serem utilizados como novas matérias-primas ou novos insumos após inertização.

A flotação é um dos processos de separação extensivamente empregado para recuperação do óleo presente nas fases dispersa e emulsionada de efluentes oleosos, e este método é utilizado nesta pesquisa visando otimizar a corrente líquida recirculada proveniente de um processo de inertização constituído de equipamentos que combinam diferentes processos de separação 
granulométrica dos sedimentos por peneiramento, com funções de redução das cargas das contaminações e reclassificação do cascalho de perfuração, por conter hidrocarbonetos e sais solúveis.

No método da flotação, partículas hidrofóbicas são seletivamente adsorvidas na superfície da bolha de gás, neste caso o ar, e arrastadas até a superfície onde são concentradas e assim removidas juntamente com a espuma. Esta operação unitária apresenta simplicidade, alta eficiência na remoção de contaminantes, capacidade para médias e altas vazões, baixo custo operacional e tempo de residência curto, o que implica em menores espaços e economia na construção (Rubio et al., 2002).

A probabilidade de uma partícula alcançar a superfície depende do sucesso de três etapas: colisão $\left(\mathrm{P}_{\mathrm{C}}\right)$, adesão $\left(\mathrm{P}_{\mathrm{A}}\right)$ e transporte $\left(\mathrm{P}_{\mathrm{T}}\right)$ (Yoon, 2000), e pode ser representada pela probabilidade de flotação $\left(\mathrm{P}_{\mathrm{F}}\right)$ de acordo com a equação 1:

$$
\mathrm{P}_{\mathrm{F}}=\mathrm{P}_{\mathrm{C}} * \mathrm{P}_{\mathrm{A}} * \mathrm{P}_{\mathrm{T}}
$$

O termo de probabilidade de colisão refere-se a colisão entre a partícula e a bolha de ar. A probabilidade desta etapa é proporcional a razão entre os diâmetros da partícula (Dp) e da bolha de ar (Db), conforme a equação 2:

$\operatorname{Pc} \propto(\mathrm{Dp} / \mathrm{Db})^{2}$

Após a colisão bolha-partícula, deverá ocorrer a formação de um agregado, o qual será coletado e analisado.

O objetivo geral desse trabalho é o desenvolvimento de técnica alternativa para tratamento e inertização do cascalho de perfuração de poço, bem como outros sedimentos impactados como solo oriundo de vazamentos.

\section{METODOLOGIA}

Neste trabalho foi utilizado o método da Flotação por Ar Induzido (FAI) para a separação dos compostos orgânicos de alta periculosidade. Através de uma coluna de acrílico com fluxo de ar ascendente e corrente de efluente descendente, foi possível o contato entre bolha-partícula. Como a corrente de ar é ascendente, a amostra é coletada na parte superior da coluna e segue para análise de teor de carbono. Além disso, são verificados multiparâmetros físico-químicos do efluente antes e depois do processo.

Foram utilizados três tipos de efluentes reais: água produzida de petróleo, água produzida de petróleo com tratamento granulométrico prévio e água industrial com tratamento granulométrico prévio. Além disso, para determinar possíveis traços de óleo na linha de ar advindas do compressor, foram feitos testes também com água destilada.

O fluxograma abaixo ilustra a metodologia utilizada no experimento: 

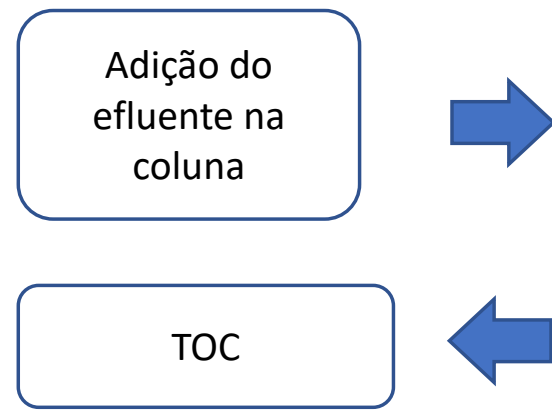

\section{Multiparâmetros}
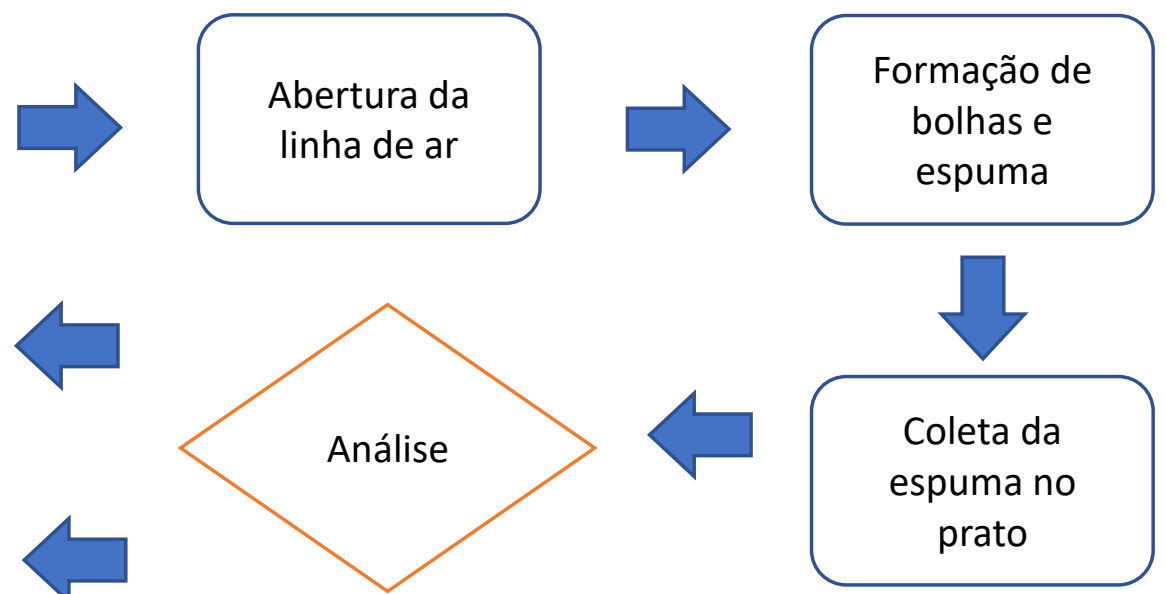

\section{RESULTADOS}

Foram analisados os teores de carbono orgânico e inorgânico das amostras coletadas no topo da coluna de flotação. Estes resultados podem ser vistos nas Figuras 1, 2, 3 e 4 a seguir, sendo o teor de carbono orgânico hachurado na horizontal, e o teor de carbono inorgânico hachurado na diagonal, oriundo possivelmente de carbonatos dissolvidos e sólidos totais vindos do processo de perfuração de poços de petróleo (formação).

Figura 1 - Teor de Carbono Orgânico (TOC) e Teor de Carbono Inorgânico (IC) para amostra de água destilada.

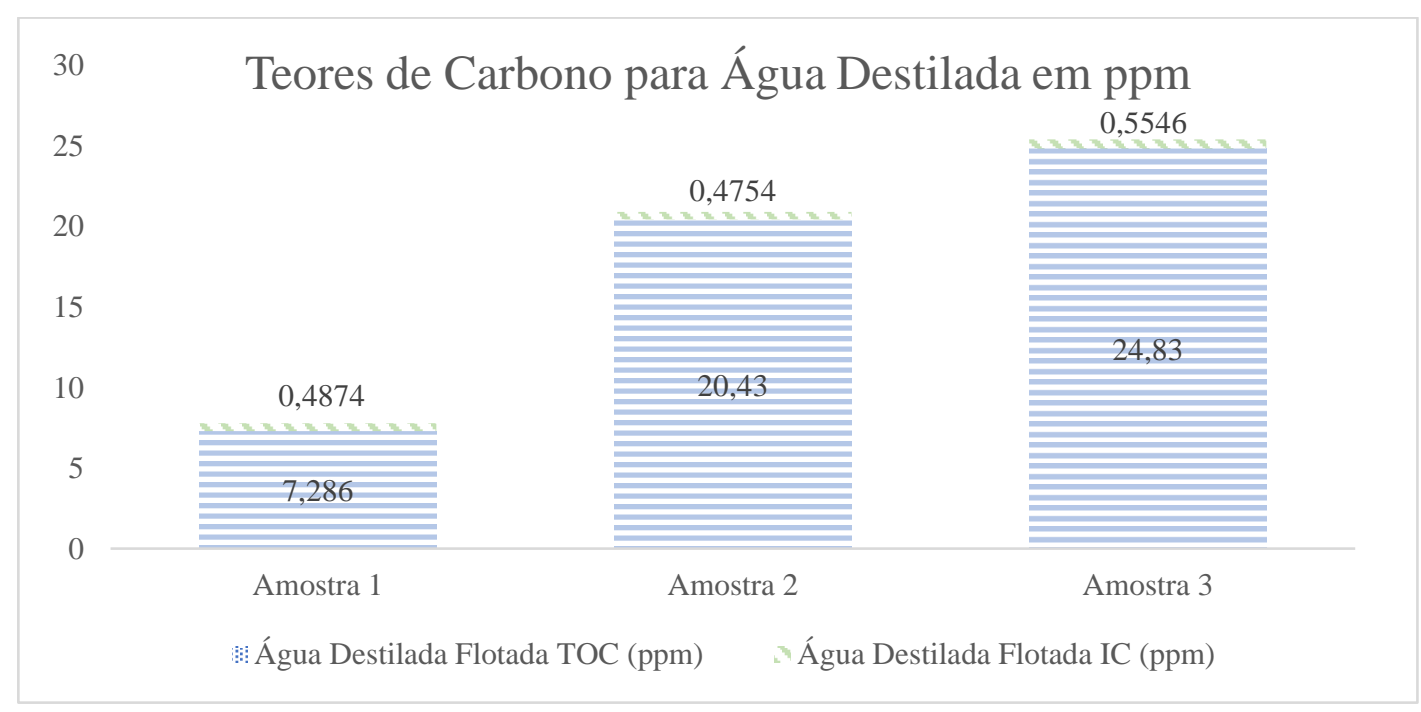

Percebe-se que há comportamento de aumento (a cada amostra) para carbono total na água destilada, onde possivelmente, a corrente de ar do compressor contribui com óleo, devido ao incremento apenas no carbono orgânico.

Além da água destilada, foram avaliados os mesmos aspectos para a água produzida de petróleo pura e tratada previamente, e ainda, água industrial tratada previamente. As figuras 2 , 3 e 4 ilustram o comportamento obtido. 
Figura 2 - Teor de Carbono Orgânico e Teor de Carbono Inorgânico para amostra de água industrial recirculada com tratamento granulométrico prévio.

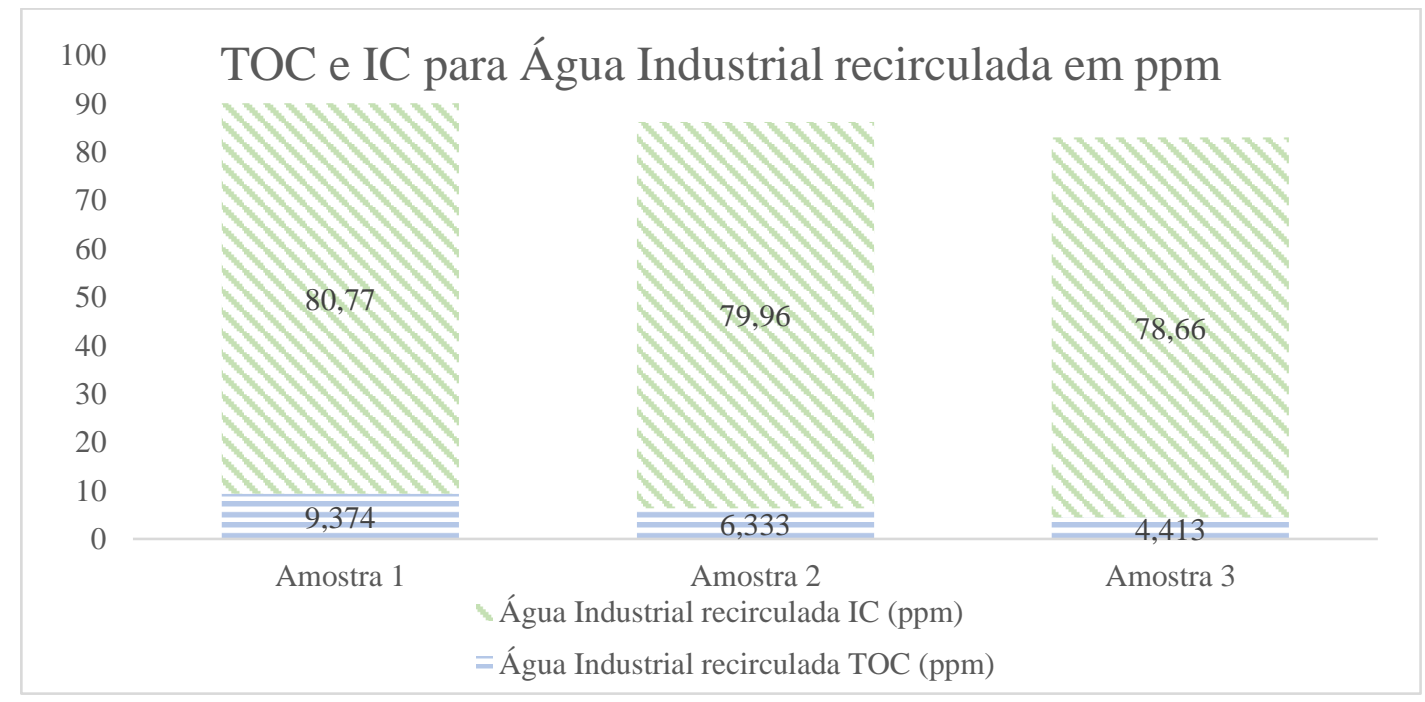

Figura 3 - Teor de Carbono Orgânico e Teor de Carbono Inorgânico para amostra de água produzida.

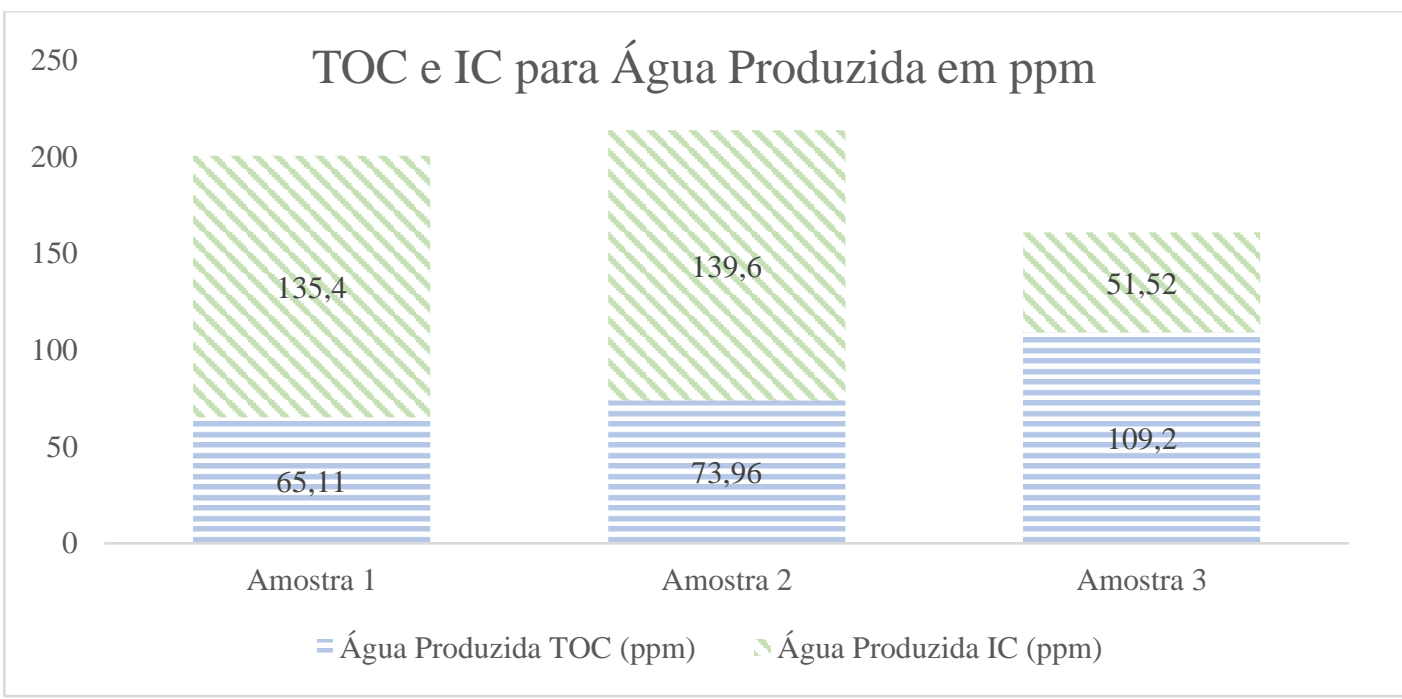


Figura 4 - Teor de Carbono Orgânico e Teor de Carbono Inorgânico para amostra de água produzida recirculada com tratamento granulométrico prévio

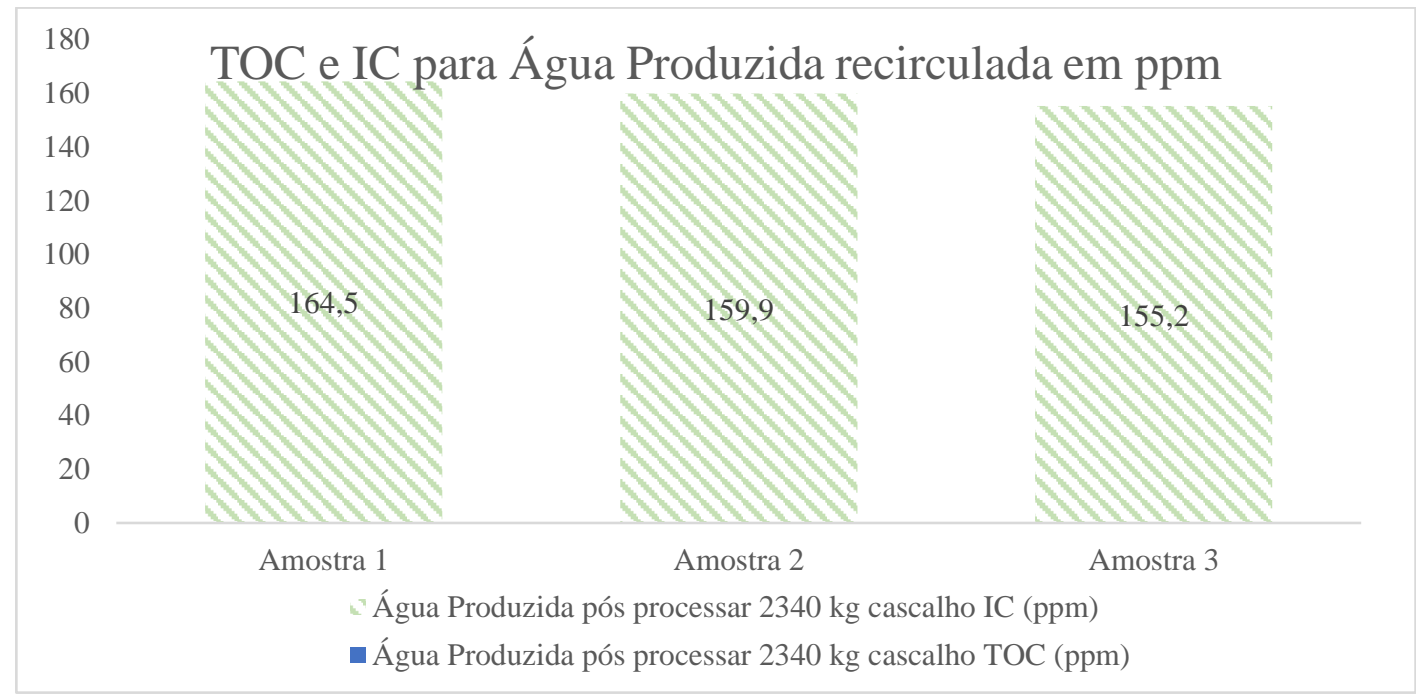

No caso da água industrial e produzida, conforme as Figuras 2, 3 e 4, mesmo que discreta, ocorre uma queda da concentração, possivelmente por efeito da remoção pelo processo de flotação. O esperável é que, com o tempo, essa queda no TOC seja mais significativa, visto que as amostras 1, 2 e 3 foram coletadas na sequência sem marcação de tempo específica.

\section{CONCLUSÃO}

De acordo com os resultados expostos, podemos afirmar que o processo de flotação é um método bastante promissor para a inertização do cascalho de petróleo. Apesar de existirem outros métodos, este é de baixo custo, simples e relativamente rápido, tornando-o uma boa alternativa.

\section{REFERÊNCIAS}

NEFF, J. M., Bioaccumulation in marine organisms Effect of contaminants from oil well produced water. Ed. Elsevier Science Ltd.: Amsterdam, pp. 1-34, 2002.

RUBIO, J.; SOUZA, M. L.; SMITH, R.W. Overview of flotation as a wastewater treatment technique. Minerals Engineering, v.15, p.139-155, 2002.

YOON, R. H., The role of hydrodynamic and surface forces in bubble-particle interaction, International Journal of Mineral Processing. v.58, 129-143, 2000. 